\title{
The influence of storm based events on the suspended sediment flux in a small scale river catchment in Ireland
}

\author{
S. T. Harrington ${ }^{1} \&$ J. R. Harrington ${ }^{2}$ \\ ${ }^{1}$ Department of Civil, Structural and Environmental Engineering, \\ Cork Institute of Technology, Ireland \\ ${ }^{2}$ School of Building and Civil Engineering, \\ Cork Institute of Technology, Ireland
}

\begin{abstract}
Fine sediment plays a key role in the transport of contaminants in rivers and the quantification of suspended sediment flux is important to understanding and managing river catchments in the context of the EU Water Framework Directive (2000/60/EC). Recent European studies identified Ireland as having a paucity of sediment and sediment associated pollutant concentration and flux data.

This paper presents the results of a continuous monitoring programme on a small scale catchment $\left(105 \mathrm{~km}^{2}\right)$ in Ireland, the River Owenabue, which is located in the South Western River Basin District. Analysis was undertaken to determine event based fluxes and their contribution to the annual flux.

The continuous monitoring programme commenced in September 2009. Analysis shows that turbidity is an accurate surrogate for suspended sediment concentration for this river and when coupled to river flow data provides estimates of the suspended sediment flux. The objective of this paper is to quantify the suspended sediment flux of a small Irish River, and to analyse the dynamic delivery sequence of storm based events. The variation of the suspended sediment flux at different temporal scales is investigated and found to be significant.

The annual suspended sediment flux was found to be 2635 tonnes $(t)$ which equates to a suspended sediment yield of $25.6 \mathrm{t} \mathrm{km}^{-2}$ year ${ }^{-1}$. The flux analysis reveals that $85 \%$ of the total annual flux is transported over $10 \%$ of the year and $69 \%$ of the flux over $5 \%$ of the year. For one event in November 2009 with a
\end{abstract}


return period flow rate of approximately 10 years, the flux is estimated at $38 \%$ of the annual flux.

Hysteresis is observed and analysed for the identified events and it is found that clockwise hysteric loop are most common implying that suspended sediment transport is most commonly limited by sediment supply.

Keywords: suspended sediment, turbidity, fluxes, loads, hysteresis, storm events.

\section{Introduction}

The importance of fine sediment transport in river systems has been highlighted in recent studies and the quantification of fine sediment transport has become a key feature in assessing, for example, water quality trends where fine sediment fluxes rather than concentrations are compared [1-3]. The theoretical flux (load) of suspended sediment transported in a river over a given time interval is given by:

$$
L_{s}=\int_{t_{1}}^{t_{2}} Q(t) \operatorname{SSC}(t) d t
$$

where $L_{s}$ is the flux for the period $\left(t_{2}-t_{1}\right), Q(t)$ is the flow rate at time $t$ and $\operatorname{SSC}(t)$ is the suspended sediment concentration at time $t$. Continuous discharge (Q) and suspended sediment concentration (SSC) data allows the most accurate estimate of 'true' flux. Continuous SSC data may be found through the use of automatic samplers (with the consequent requirement for laboratory testing) which can be expensive to operate or through the monitoring of a surrogate such as turbidity which by comparison is significantly less expensive and onerous.

Linear relationships between turbidity and suspended sediment concentration have been developed in various studies [4, 5]. Variations in grain size distribution (particularly at the coarser sizes) associated with floods, may cause non-linear relationships to occur between turbidity and SSC although Lewis [5] reports that, in practice, linear models work quite well. In this paper, SSC values are low $\left(<850 \mathrm{mg} \mathrm{L}^{-1}\right)$ and based on visual analysis the suspended sediment on the filters remains fine $(<63 \mu \mathrm{m})$ even during flood events and thus a linear relationship between turbidity and SSC is suitable.

In an Irish context, work in this area has been limited and annual fluxes using continuous data have not yet been presented and European studies have identified Ireland as having a paucity of sediment and sediment associated pollutant concentration data [6]. Recent work by the Sediment Research Group at CIT estimated suspended sediment fluxes (SSF) for seven rivers in the South Western River Basin District, Ireland. The work was based on manual storm based sampling and used the flow duration - rating curve method of flux estimation. The annual flux for the Owenabue catchment was estimated to be $2305 \mathrm{t} \mathrm{yr}^{-1}$ (tonnes per year) which equates to a suspended sediment catchment yield (SSY) of $22.4 \mathrm{t} \mathrm{km}^{-2} \mathrm{yr}^{-1}$ (tonnes per square kilometre per year). SSY for a number of the uncontrolled catchments in the SWRBD were estimated to range from 17 to $25 \mathrm{t} \mathrm{km}^{-2} \mathrm{yr}^{-1}$. 
The objectives of this paper are to quantify the SSF and to analyse and present the results of sediment flux dynamics and delivery of a small Irish River. The contribution of high flow storm based events is analysed and the SSC-Q relationships are investigated using hysteretic loops at different temporal scales.

\section{Catchment characteristics}

The Owenabue catchment is located in the south of Ireland as shown in fig. 1. The $23 \mathrm{~km}$ long river flows in an easterly direction and drains to the harbour of Ireland's second largest city, Cork. The $105 \mathrm{~km}^{-2}$ catchment is a small uncontrolled catchment with natural drainage with an average flow rate of $2.29 \mathrm{~m}^{3} \mathrm{~s}^{-1}$. The catchment itself is quite steep to the north and south of the east flowing river. Average annual rainfall for the catchment is $1207 \mathrm{~mm}_{\text {year }}{ }^{-1}$ with rainfall levels approximately twice as large in winter as in summer. The basin sub-soil consists mainly of namurian, devionian, carboniferous shales and sandstones and some devionain till, with surface soil types including acid brown earths, brown podzolics and marl type soils. Primary land uses in the basin are tillage, pasture and forestry with small pockets of urban areas.

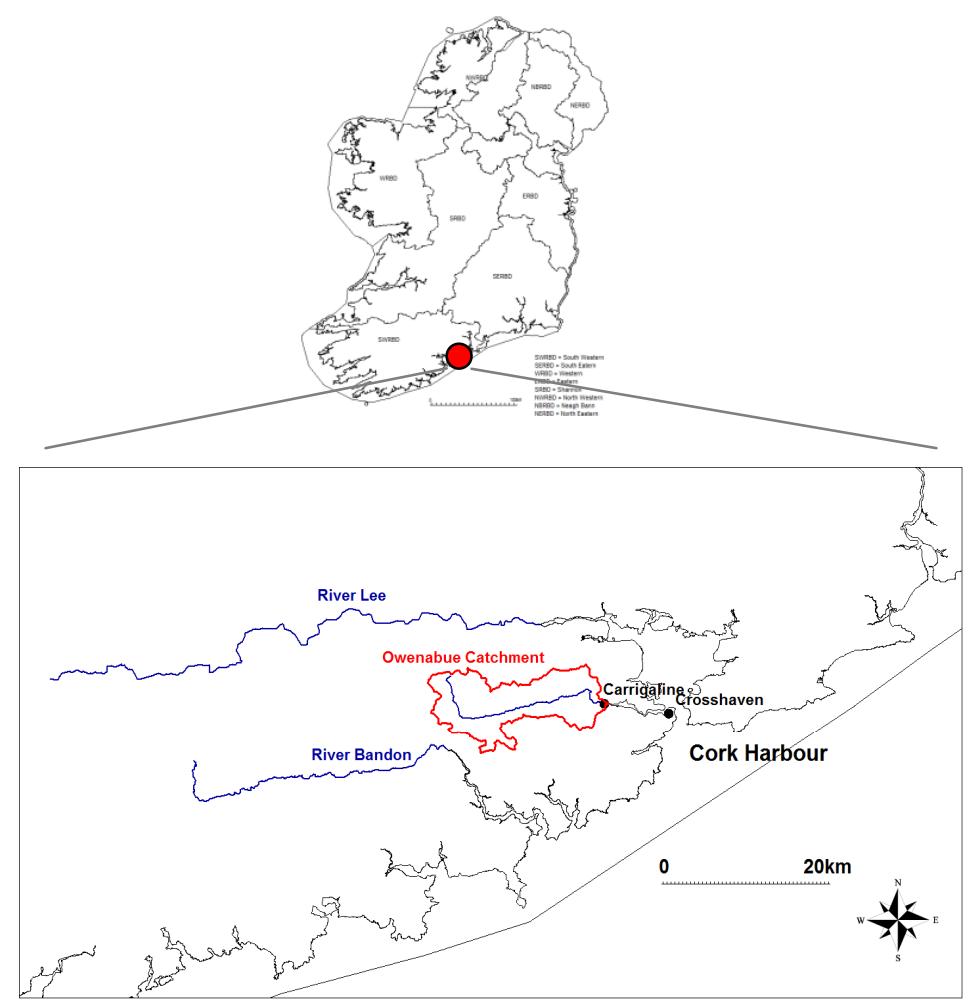

Figure 1: Location of the Owenabue catchment. 
The Ballea Bridge Lower hydrometric station on the River Owenabue consists of an automatic water level recorder which is maintained and operated by the Irish Office of Public Works. The station catchment area is $103 \mathrm{~km}^{2}$ and records are available from 1956 to date. Water level is recorded at 15 minute intervals and converted to flow rate using a site specific stage discharge curve.

\section{Methodology}

The data collection period was from the $15 / 9 / 2009$ to $15 / 9 / 2010$ during which 49 manual surfaces grab samples were collected for the purposes of calibrating turbidity to SSC. Each manual sample was laboratory tested for SSC using Method 2540 D of the American Public Health Association (APHA). A vacuum pump was used to reduce filtering time for samples with high suspended sediment values.

In-situ turbidity was continuously monitored at the Ballea Bridge Lower hydrometric station using a Campbell Scientific OBS 3+ probe connected to a CR800 logger recording at 15 minute intervals. In-situ turbidity measurements were converted to SSC using a linear relationship developed by comparing the results from the in-situ turbidity probe with the measured SSC from manually collected samples. Details of the analysis are presented in Section 4.1 below. Suspended sediment fluxes were determined by applying eqn. (1).

In order to analyse the contribution of storm based events to the annual flux the individual events must first be identified and defined. This can be undertaken using different criteria such as applying Q, SSC or SSF limits. In this paper, events are identified as occurring when the flow rate equals or exceeds the $10 \%$ flow exceedance level for the river $\left(8.23 \mathrm{~m}^{3} \mathrm{~s}^{-1}\right)$. The event is defined as beginning when the SSF exceeds the flux rate which occurs $50 \%$ of the time (0.014 tonnes per 15 minutes) during the six hydrological winter months (October to March inclusive). These six months were selected for two reasons: firstly to filter smaller events from the record for analysis purposes and secondly to limit analysis of events with excessive durations, particularly during the winter. Similar approaches, for example, have been adopted by others $[7,8]$.

\section{Results and discussion}

The recorded rainfall for the study period was $1181 \mathrm{~mm}$ at the nearest rain gauge station at Cork Airport which is $98 \%$ of the annual mean of $1207 \mathrm{~mm}$. The largest daily rainfall recorded over the study period was $51.3 \mathrm{~mm}$, with 12 days when daily rainfall exceeded $20 \mathrm{~mm}$. The average flow rate for the hydrological year analysed was $3.08 \mathrm{~m}^{3} \mathrm{~s}^{-1}$ which is $134 \%$ of the long term average for the river. This above average flow rate can be explained by reduced infiltration of rainfall which was observed to occur during the study period thus increasing overland runoff. 


\subsection{Turbidity - suspended sediment concentration calibration}

The results of the analysis of the 49 manual samples collected, allows comparison between SSC and in-situ turbidity. Samples were collected over a large and representative discharge range on the river from 0.37 to $16.66 \mathrm{~m}^{3} \mathrm{~s}^{-1}$. In-situ turbidity was found to be an excellent predictor of SSC with an $\mathrm{r}^{2}$ value for the relationship of 0.967 determined.

\subsection{Suspended sediment flux estimates}

Fig. 2 presents the daily suspended sediment flux for the study period. Days when a manual sample was collected are marked with an $\mathrm{X}$ and highlights the range over which manual samples were collected. Seasonally streamflow is greatest between October and March and typically lower from April to September on the River Owenabue, which is typical of Irish and UK rivers. During the study period October exhibited the highest discharge being $160 \%$ of the discharge in November, which yielded the highest monthly SSF, as shown in fig. 3.

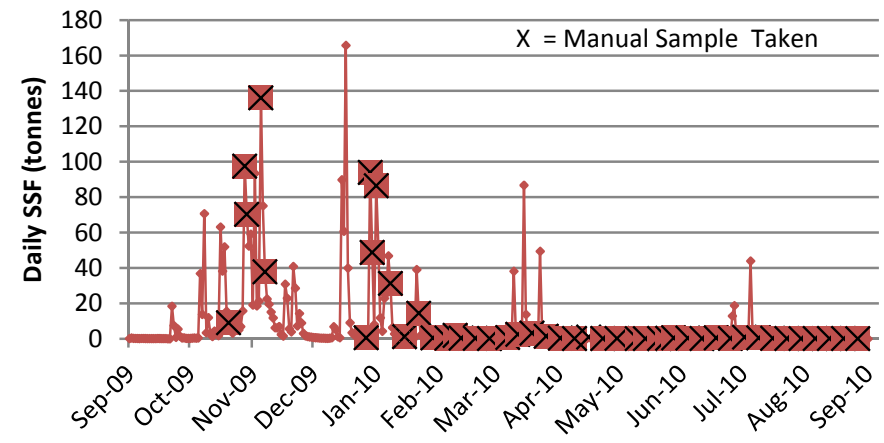

Figure 2: $\quad$ Daily suspended sediment flux for the study period.

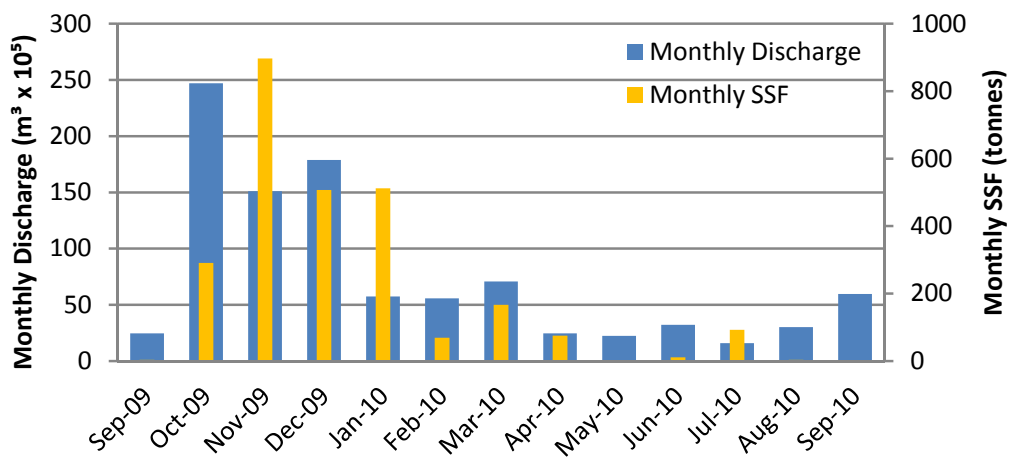

Figure 3: $\quad$ Monthly discharge and SSF for the study period. 
The annual SSF passing the Ballea Bridge Lower gauging station was found to be 2635 tonnes $(\mathrm{t})$ which equates to a SSY of $25.6 \mathrm{t} \mathrm{km}^{-2} \mathrm{a}^{-1}$. The flux analysis reveals that $85 \%$ of the total annual flux is transported over $10 \%$ of the year and $69 \%$ of the flux over $5 \%$ of the year. This is common for small catchments and similar results have been reported in other studies [9, 10]. Fig. 3 indicates that transport in the river is primarily (but not exclusively) flow dependant as the largest SSF values occur during the winter months when flows are largest.

\subsection{High flow storm based events}

Table 1 presents summary details for the ten storm events identified using the methodology presented in Section 3 above. The events range in duration from 51

Table 1: Summary details of identified storm events on the River Owenabue.

\begin{tabular}{|c|c|c|c|c|c|c|c|}
\hline $\begin{array}{l}\text { Event } \\
\text { No. }\end{array}$ & $\begin{array}{l}\text { Event Start } \\
\text { Date and } \\
\text { Time }\end{array}$ & $\begin{array}{c}\text { Duration } \\
\text { (hours) }\end{array}$ & $\begin{array}{c}\text { Peak flow } \\
\text { percentile } \\
\text { exceedance }\end{array}$ & $\begin{array}{c}\text { No. } \\
\text { of } \\
\text { peaks }\end{array}$ & $\begin{array}{l}\text { Total SSF } \\
\text { (tonnes) }\end{array}$ & $\begin{array}{l}\text { Average } \\
\text { Daily SSF } \\
\text { (tonnes) }\end{array}$ & $\begin{array}{c}\text { Average } \\
\text { Daily Q } \\
\left(\mathrm{m}^{3} \times 10^{3}\right)\end{array}$ \\
\hline & $20 / 10 / 2009$ & & & & & & \\
\hline \multirow[t]{2}{*}{1} & $00: 45$ & 137.5 & $5 \%$ & 3 & 140 & 24.4 & 453 \\
\hline & $29 / 10 / 2009$ & & & & & & \\
\hline \multirow[t]{2}{*}{2} & $17: 15$ & 761.75 & $2 \%$ & 7 & 991 & 31.2 & 824 \\
\hline & $01 / 12 / 2009$ & & & & & & \\
\hline \multirow[t]{2}{*}{3} & 08:15 & 244.75 & $10 \%$ & 6 & 167 & 16.4 & 698 \\
\hline & $28 / 12 / 2009$ & & & & & & \\
\hline \multirow[t]{2}{*}{4} & $21: 00$ & 185 & $2 \%$ & 2 & 369 & 47.9 & 758 \\
\hline & $12 / 01 / 2010$ & & & & & & \\
\hline \multirow[t]{2}{*}{5} & $04: 45$ & 347.5 & $2 \%$ & 5 & 138 & 9.5 & 785 \\
\hline & $04 / 02 / 2010$ & & & & & & \\
\hline \multirow[t]{2}{*}{6} & $12: 45$ & 51 & $10 \%$ & 1 & 55 & 25.7 & 434 \\
\hline & $24 / 03 / 2010$ & & & & & & \\
\hline \multirow[t]{2}{*}{7} & $00: 15$ & 69.75 & $10 \%$ & 1 & 44 & 15.1 & 312 \\
\hline & $29 / 03 / 2010$ & & & & & & \\
\hline \multirow[t]{2}{*}{8} & $02: 45$ & 78.5 & $2 \%$ & 1 & 106 & 32.4 & 473 \\
\hline & $06 / 04 / 2010$ & & & & & & \\
\hline \multirow[t]{2}{*}{9} & 01:00 & 80 & $5 \%$ & 1 & 56 & 16.9 & 472 \\
\hline & $18 / 07 / 2010$ & & & & & & \\
\hline 10 & $10: 15$ & 53 & $10 \%$ & 1 & 48 & 21.7 & 321 \\
\hline
\end{tabular}

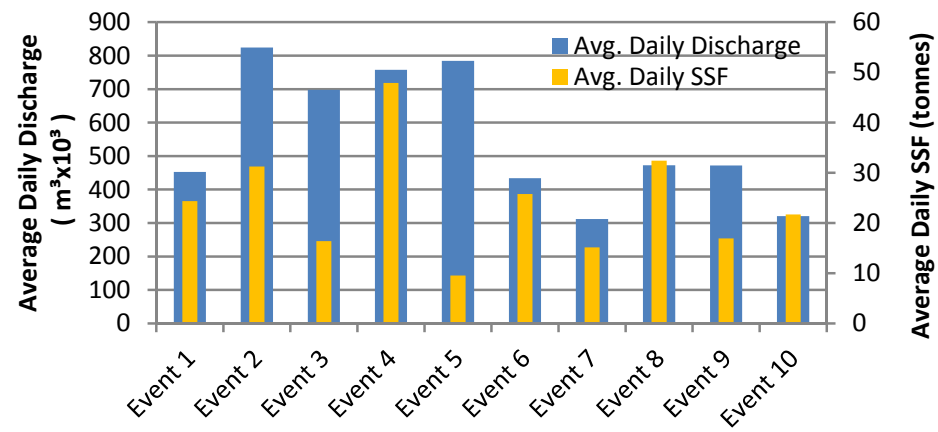

Figure 4: Daily discharge and SSF for the ten events identified. 
to 763 hours, with five of the events lasting for more than 5 days, all occurring before February 2010. The ten events account for $22.9 \%$ of the study period duration and $80 \%$ of the total SSF for the study period. The events identified display different characteristics including single and multiple peak events, some with secondary SSC peaks unexplained by Q. The average daily Q and SSF are shown in fig. 4 and suggest that the relationship between Q and SSF changes from event to event.

\subsection{Scale variations of suspended sediment concentrations}

Variations in SSC independent of Q across multiple scales have been widely reported in the literature [9-11]. Analysis was undertaken to determine if such temporal variations occur between SSC and Q on the River Owenabue. The hydrograph and suspended sediment signal for each event is identified by its event number and presented in fig. 5 and shows that there is a clear correlation between SSC and Q where in general there is a response in the SSC signal to increased Q values. For example, event 1 lasting from $20-25^{\text {th }}$ October 2009, the first to occur in the hydrological year, has a peak flow rate of $11.1 \mathrm{~m}^{3} \mathrm{~s}^{-1}$ and an associated peak SSC of $389 \mathrm{mg} \mathrm{L}^{-1}$. Later in the study period, similar flow events have a much lower associated SSC peak. Examples of this are: event 6 in February which has a peak flow rate of $10.04 \mathrm{~m}^{3} \mathrm{~s}^{-1}$ and a peak SSC of $251 \mathrm{mg}$ $\mathrm{L}^{-1}$ and event 8 at the end of March which has a peak $\mathrm{Q}$ of $11.65 \mathrm{~m}^{3} \mathrm{~s}^{-1}$ with a peak SSC of $245 \mathrm{mg} \mathrm{L}^{-1}$. This shows that the SSC-Q relationship is seasonally variable with higher SSC for a given flow rate in the early winter months.

Event 4, starting $28^{\text {th }}$ December 2009 has the largest average daily flux at 47.9 tonnes per day, which is over $32 \%$ larger than the next largest event by daily flux. The flow rate during this storm exceeded the $2 \%$ flow exceedance limit for the river. Event 4 occurred only a month after the end of event 2 and only 17 days after event 3 . Event 2 transported 991 tonnes and had an average $\mathrm{SSC}$ value of $30 \mathrm{mg} \mathrm{L}^{-1}$ while event 3 has a low average SSC value $\left(20 \mathrm{mg} \mathrm{L}^{-1}\right)$ and combined with its shorter duration transported a smaller quantity of suspended sediment (167 tonnes).

Event 3 does not appear to significantly reduce the quantity of suspended sediment available for transport during event 4 and this is due to the shorter duration during event 3 and the previous partial exhaustion of suspended sediment by event 2 . When event 4 began significant sediment recharge appears to have taken place and peak SSC values for the event reach $370 \mathrm{mg} \mathrm{L}^{-1}$, with the average SSC value for event 4 of $45 \mathrm{mg} \mathrm{L}^{-1}$. This event is in stark contrast to event 5 which occurs 7 days after the end of event 4 where the SSF is only $20 \%$ of that of event 4. For event 5, four peaks in Q occur, between 12 and $14 \mathrm{~m}^{3} \mathrm{~s}^{-1}$ and a progressive reduction in SSC is observed.

This shows that changes in the SSC-Q relationship occur within and across events. For example, sediment recharge appears to occur before event 4 and the SSF observed across events $2-4$ shows that events are significantly influenced by the event immediately preceding them. 
180 Monitoring, Simulation, Prevention and Remediation of Dense and Debris Flows IV
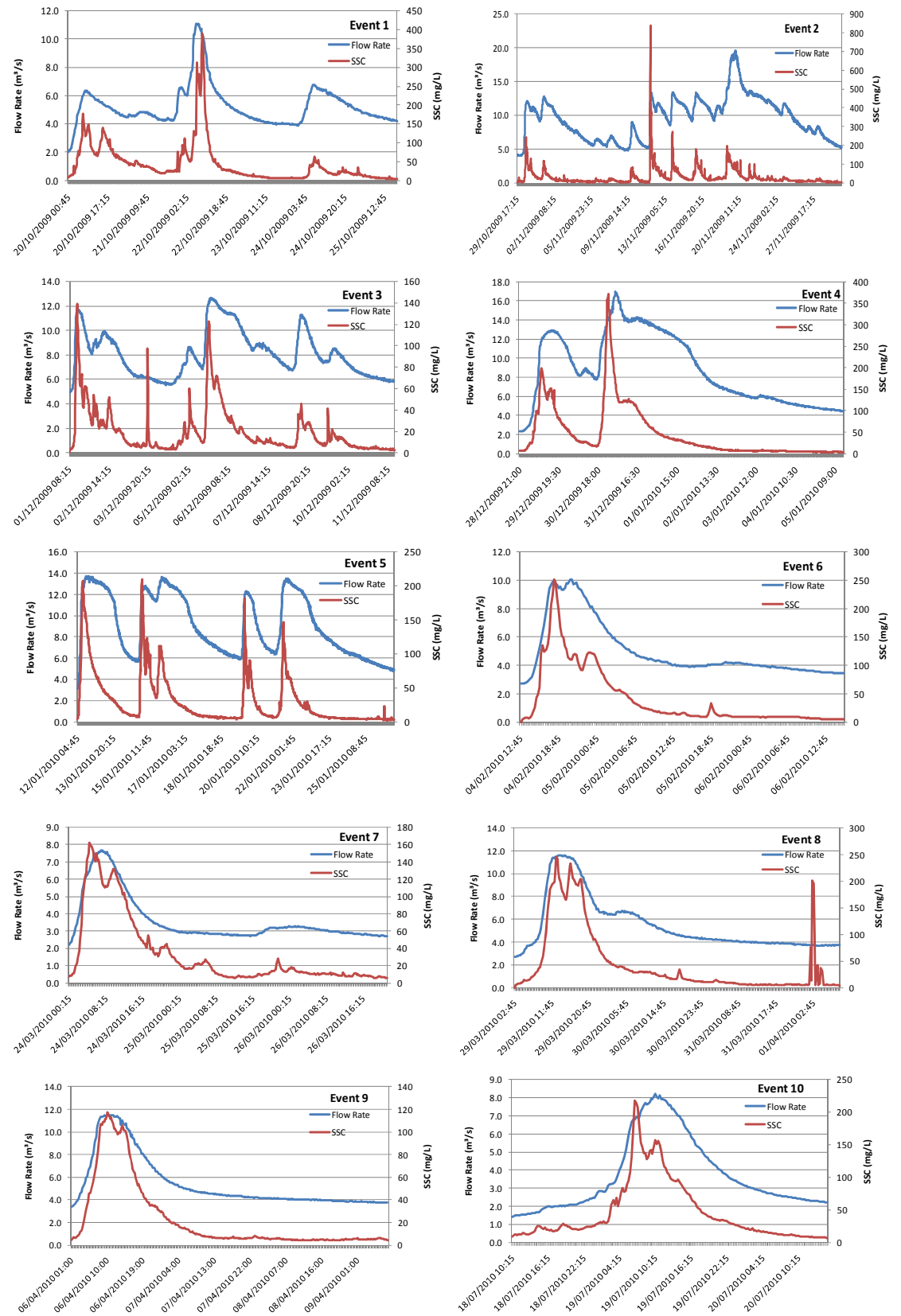

Figure 5: Event hydrographs and SSC plots for the ten events identified. 


\subsection{Hysteresis of the SSC-Q relationship}

Hysteresis is commonly observed in the relationship between SSC and Q when peak SSC occurs either before or after peak Q. Williams [13] provides a comprehensive overview of the hysteretic phenomenon. He defined 5 classes of SSC-Q relationships. The main three relationships are: straight or curved single lines, clockwise loops and anticlockwise loops. Klein [14] found that anticlockwise hysteretic loops were the result of the catchment hill slopes being the primary source where the travel time for the sediment material is orders of magnitude slower than the channel itself, which results in a lag of SSC behind Q. Alternatively, Steegen et al. [11] explains clockwise hysteresis as occurring for similar reasons. Distant source material has a longer flow path compared to nearer sources, and will thus have an increased probability of being deposited upstream of the measuring station, thus leading to reduced SSC on the falling limb of the hydrograph. The most common explanation for clockwise loops is a combination of the phenomena of sediment exhaustion and the close proximity of the sediment source to the monitoring station $[4,9,12]$.

Of the total of 28 peaks across the 10 events, 17 are clockwise loops, 2 anticlockwise loops, 4 single line loops and 5 mixed or figure of eight type loops. Fig. 6 presents the hysteretic loops for the most complex events, events 1 , 2, 3 and 5. Clockwise loops dominate high flow storm based events implying that much of the sediment source for the catchment are located within the river and that river flow rate is the primary factor controlling SSF.

Analysis of the SSC-Q rating curves was undertaken by fitting a non-linear power type regression curve to the data for each event. Considerable variation was found in the $a$ parameter with little variation in the $b$ parameter, values of approximately 3 being common, which has been suggested to indicate the high erosion potential of the river [15].

\subsection{Secondary suspended sediment peaks}

It can be observed that the initial SSC peak for many of the events identified is followed closely by a secondary peak which does not correspond to an increase in flow. This is clearly observed in events $1,5,7,8,9$ and 10 .

In fig. 6 , these secondary peaks are clearly seen in the peak 2 loop of event 1 , where after peak flow passes and flow and SSC begin to decline the secondary peak in SSC causes the loop to increase to the SSC maximum. For this event the secondary SSC peak is $20 \%$ larger than the initial SSC peak and occurs 2.75 hours after the Q peak and 1.75 hours after the initial SSC peak. This may indicate that for this event a primary source of sediment is located upstream of the gauging station. This is commonly observed in small or flashy river basins [12] and there are a number of possible causes of such secondary peaks. The first explanation is that the sediment source is located far from the river in the upland catchment or far upstream of the measuring station. When the sediment reaches the river, from the catchment, the flow rate may already be decreasing and thus by the time the sediment reaches the recording station the flow may have 
182 Monitoring, Simulation, Prevention and Remediation of Dense and Debris Flows IV
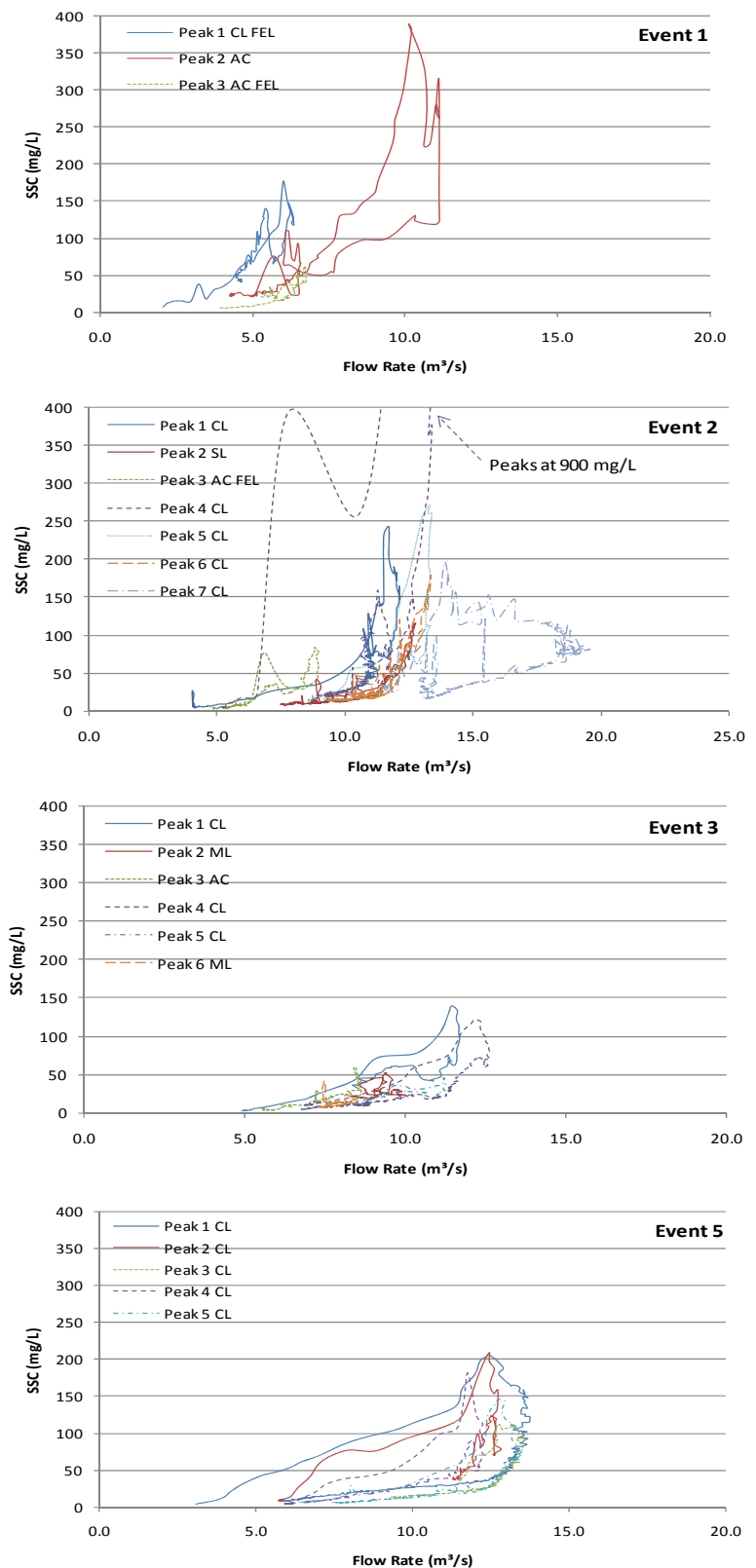

Figure 6: Hysteretic loops for the ten events identified. (Note: SL $=$ single line, $\mathrm{CL}=$ clockwise loop, $\mathrm{AC}=$ anticlockwise loop, $\mathrm{FEL}=$ figure of eight loop and $\mathrm{ML}=$ mixed loop. 
decreased significantly. This will result in a wave of sediment rich water, without an increase in flow rate.

The lag time between initial and secondary peaks is not constant with lags of 2 to 8 hours observed with the secondary peak generally smaller than the initial peak. It seems most likely that a primary source of sediment is some distance from the recording station given the frequency of occurrence of secondary peaks although other possible explanations such as small tributaries delivering late supply of sediment, river bank caving on the falling limb and spatial variation in rainfall within the catchment cannot be discounted.

\section{Conclusions}

The objective of this paper was to quantify the SSF of a small Irish River, and to analyse the dynamic delivery sequence of storm based events.

Turbidity has been found to be an excellent surrogate for SSC on this river and this relationship was used to generate continuous SSC data which when coupled to river flow rate yields estimates of SSF for individual storm based events.

Analysis shows that the contribution of storm based fluxes is significant to the SSF for the study period, $85 \%$ of the total SSF being transported in $10 \%$ of the time.

The SSC-Q relationship varies temporally at multiple scales; within events, from event to event and seasonally. Hysteretic analysis shows that during the study period clockwise events dominate implying the close proximity of the sediment source to the monitoring station, these sediment sources are the primary contributor to the SSF. However, secondary SSC peaks are often observed, which are generally smaller than the initial SSC peak, and contribute smaller but none the less frequent quantities of suspended sediment to the total SSF.

\section{Acknowledgements}

The authors wish to acknowledge the research funding received from the Government of Ireland/Institutes of Technology Technological Sector Research Strand I Postgraduate R\&D Skills Programme and the support received from the Irish Office of Public Works in providing river flow and associated data.

\section{References}

[1] Walling, D.E., Russell, M.A., Webb, B.W., 'Controls on the nutrient content of suspended sediment transported by British rivers', Science of the Total Environment, Vol. 266, 113-123, 2001.

[2] Zonata, R., Collavini, F., Zaggia, L., Zuliani, A., 'The effect of floods on the transport of suspended sediments and contaminants: A case study from 
the estuary of the Dese River (Venice Lagoon, Italy)', Environmental International, Vol. 31 pp. 948-958, 2005.

[3] Horowitz, A.J., 'Determining annual suspended sediment and sedimentassociated trace element and nutrient fluxes', Science of the Total Environment, Vol. 400, 315-343, 2008.

[4] Lenzi, M.A., Marchi, L., 'Suspended sediment load during floods in a small stream of the Dolomites (northeastern Italy)', Catena 39, 267-282, 2000.

[5] Lewis, J., 'Turbidity controlled sampling for suspended sediment load estimation'. In Bogen, J., Tharan, F., Walling, D., (Eds), Erosion and Sediment Transport Measurement in Rivers: Technology and Methodological Advances. Proc. Oslo Workshop, 19-20 June 2002, vol. 283. IAHS Publ. pp. 13-20, 2003.

[6] Borgvang, S.A., Skarbøvik, E., Pengerud, A., 'Comprehensive Study on Riverine Inputs and Direct Discharges (RID): Presentation and Assessment of the OSPAR Contracting Parties' RID 2006 Data' Report no. 376, prepared by Bioforsk for the OSPAR Commission, 2008.

[7] Smith, B.P.G., Naden, P.S., Leeks, G.J.L., Wass, P.D., The influence of storm events on fine sediment transport, erosion and deposition within a reach of the River Swale, Yorkshire, U.K., Science of the Total Environment, Vol. 314-316, pp. 451-474, 2003.

[8] Zabaleta, A., Martínez, M., Uriarte, J.A., Antigüedad, I., 'Factors controlling suspended sediment yield during runoff events in small headwater catchments of the Basque County', Catena, Vol. 71, 179-190, 2007.

[9] Rodríguez-Blanco, M.L., Taboada-Castro, M.M., Pallerio, L., TaboadaCastro, M.T., 'Temporal changes in suspended sediment transport in an Atlantic catchment, NW Spain', Geomorphology, Vol. 123, 181-188, 2010.

[10] Rovira, A., Batalla, R.J., 'Temporal distribution of suspended sediment transport in a Mediterranean basin: The Lower Tordera (NE Spain)', Geomorphology 79, 58-71, 2006.

[11] Steegen, A., Govers, G., Nachtergaele, J., Takken, I., Beuselinck, L., Poesen, J., 'Sediment export by water from an agricultural catchment in the Loam Belt of central Belgium', Geomorph., Vol. 33, 25-36, 2000.

[12] Hudson, P.F., 'Event sequence and sediment exhaustion in the lower Panuco Basin, Mexico', Catena, Vol. 52, 57-76, 2003.

[13] Williams, G.P., 'Sediment concentration versus water discharge during single hydrologic events in rivers', J. Hydrology, Vol. 111, pp. 89-106, 1989.

[14] Klein, M., 'Anti clockwise hysteresis in suspended sediment concentration during individual storms: Holbeck Catchment, Yorkshire, England', Catena, Vol. 11, 251-257, 1984.

[15] Asselman, N.E.M., Fitting and interpretation of sediment rating curves, Hydrology, 234, pp. 228-248, 2000. 